\title{
Development of a high precision tabletop versatile CNC wire-EDM for making intricate micro parts
}

\author{
Yunn-Shiuan Liao, Shun-Tong Chen and Chang-Sheng Lin \\ Department of Mechanical Engineering, National Taiwan University, 1, Sec 4, \\ Roosevelt Road, Taipei, 106, Taiwan \\ E-mail: liaoys@ntu.edu.tw
}

Received 9 April 2004, in final form 27 August 2004

Published 16 November 2004

Online at stacks.iop.org/JMM/15/245

\begin{abstract}
The micro electrical discharge machining (micro-EDM) process has been proved to be appropriate for making 3D micro parts that are difficult and even impossible to manufacture by other processes. In this paper a high precision tabletop CNC wire electrical discharge machine (wire-EDM) designed specifically for machining complex shaped micro parts or structures is developed. In the machine developed, a novel micro wire-cutting mechanism is designed, an approach to control wire tension by magnetic force is proposed and a servo feed control strategy, in accordance with the measured gap voltage, is designed and implemented. To verify the functions and capabilities of the machine developed, several thick micro outer and internal spur gears and a rack are machined. It shows that the taper angle along the wall or cavity of a part that appears when other micro-EDM processes are applied can be avoided. A very good dimensional accuracy of $1 \mu \mathrm{m}$ and a surface finish of $R_{\max }$ equal to $0.64 \mu \mathrm{m}$ are achieved. The satisfactory cutting of a miniature $3 \mathrm{D}$ pagoda with a micro-hooked structure also reveals that the machine developed is versatile, and can be used as a new tool for making intricate micro parts.
\end{abstract}

(Some figures in this article are in colour only in the electronic version)

\section{Introduction}

Many advantages arise when a part is miniaturized, such as energy and space savings, accelerating chemical reactions, attractive appearance, cost effectiveness, etc, and lead to lightweight, thin, short and small products, especially useful in present-day IC, communication and biotechnology industries. Alongside this trend, it becomes increasingly difficult to manufacture the miniature parts: particularly when the shape of the part is $3 \mathrm{D}$ and intricate. The micro-EDM process is one of the alternatives often selected from among all the nontraditional processes to machine micro parts $[1,2]$. In the existing micro-EDM process, wire electrical discharge grinding (WEDG) is used to make a micro electrode [3]. The micro electrode thus manufactured is used for making micro holes by EDM drilling, or for making micro slots and microcomplex molds by micro-EDM milling process. Since the micro electrode will consume continuously, compensation for electrode wear is needed to maintain high dimensional accuracy. Yu et al [4] and Bleys et al [5] proposed similar compensation strategies by limiting the wear to taking place at the bottom face of the electrode only. Nonetheless, this increases the machining time. Also, the problem of taper angle along the wall of a part or cavity still exists and is very difficult if not impossible to avoid [6]. Furthermore, the micro-EDM milling process followed by the use of WEDG is not appropriate when there is a large amount of material to be removed. In this case, a very long electrode is needed to compensate for tool wear but then vibration or instability of the electrode may occur.

Another category of micro-discharge machining is a micro-wire-EDM process in which the cutting is conducted by a micro wire of $\varnothing 0.02 \mathrm{~mm}-0.05 \mathrm{~mm}$. Several EDM machine tool builders such as Agie Charmilles Ltd of Switzerland, 


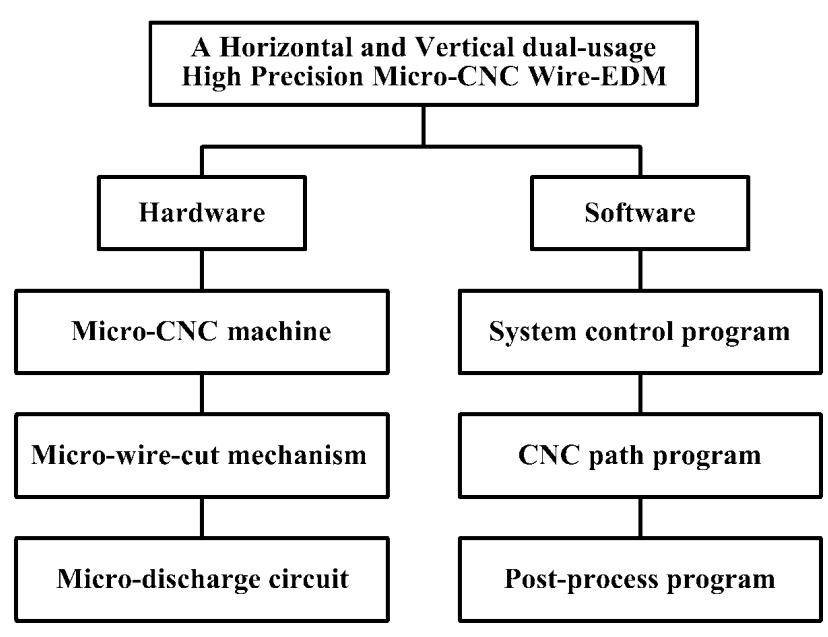

Figure 1. The structure of the tabletop CNC wire-EDM developed.

Fanuc Ltd and Sodick Inc. of Japan have developed this kind of machine. However, as is similar to conventional wire-EDM machines, all the commercially available micro-wire-EDM machines can only work vertically [7-10]. Depending on the mounting of the workpiece on the table and the features of the part to be manufactured, in some cases machining via horizontal/diagonal wire cutting is more convenient, and accuracy is more easily maintained. Wire tension is strongly related to wire bending and vibration. This in turn affects the stability of the process and machining accuracy. It is very difficult to accurately control the tension in a micro brass wire with a diameter smaller than $0.02 \mathrm{~mm}$ by the conventional roll driver and brake mechanism. Kinoshita and Hayashi [11] proposed the use of a swing-arm incorporated with a set of laser displacement gauges for the purpose of wire tension control. A load cell was employed by Yan et al [12]. However all these approaches are costly, and they are not applicable to small machines specifically designed for making micro parts, as there is insufficient space to implement the measurement sensors and set-up.

A high precision tabletop versatile $\mathrm{CNC}$ wire-EDM for making intricate micro parts is developed in the paper. A novel mechanism that enables the wire to cut vertically, horizontally or even diagonally is designed and implemented. Details of the approaches to ensure stable movement of wire including tension control are also described. Using the machine developed, once the workpiece is mounted on the table of the machine, the partially finished micro part need not be unloaded and repositioned until all the planned tasks are completed. This increases the degree of freedom of machining, decreases the time of loading and unloading and, most importantly, the dimensional and geometrical accuracy of the machined part can be guaranteed. The cutting of various micro parts is conducted, and the resulting dimensional accuracy, geometrical accuracy and surface finish are evaluated.

\section{Machine development}

The configurations of the machine developed are depicted in figure 1. The hardware includes three major parts: a tabletop CNC machine, a dual-usage micro-CNC wire-cutting

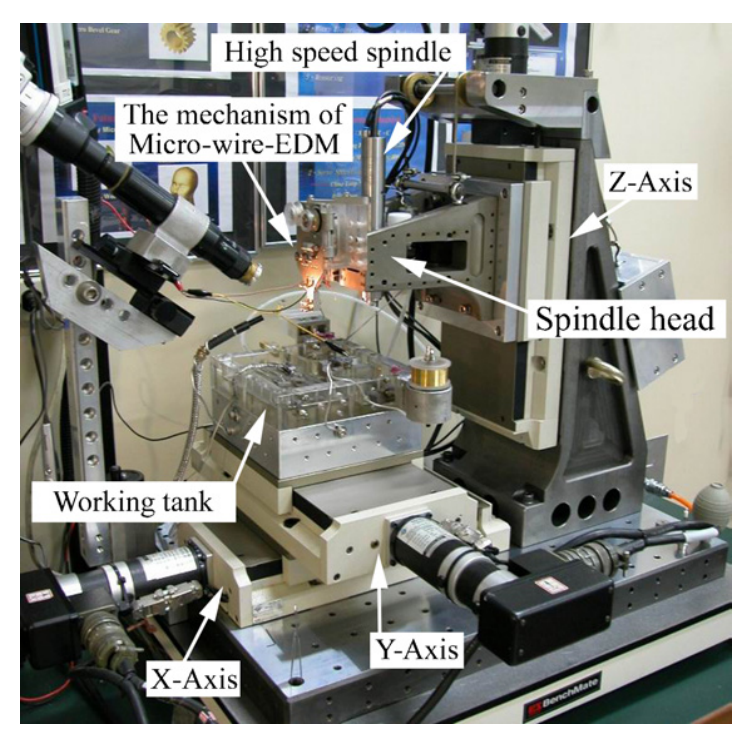

Figure 2. The high precision tabletop CNC machine and micro-wire-cutting mechanism.

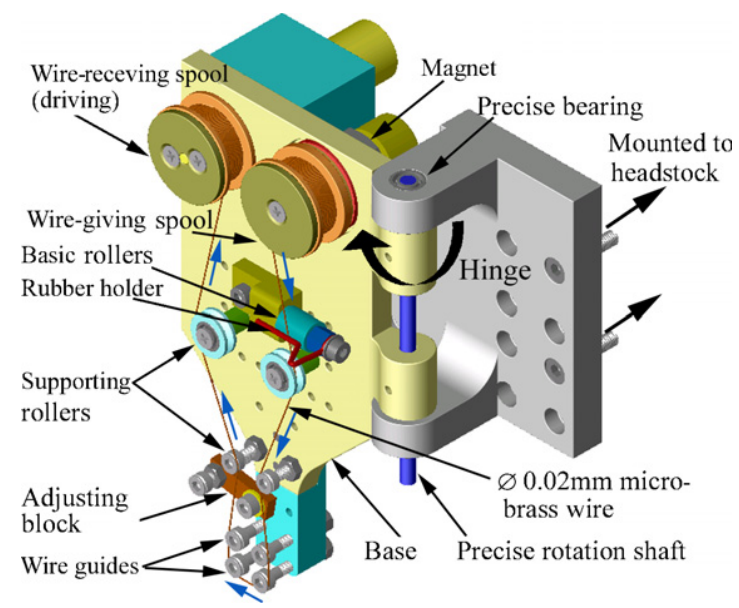

Figure 3. A novel design micro-wire-cutting mechanism.

mechanism and a set of micro discharge circuits. The software also consists of three sub-systems, namely, a system control program, a CNC path program and a post-process program.

\subsection{Tabletop CNC machine}

Figure 2 shows a photograph of the machine developed. Due to the modularized design of the system, the machine can perform general micro-milling, micro-EDM, micro-high speed milling, micro-EDM milling etc as well as micro-wire-EDM. But this paper focuses on micro-wire-EDM only.

\subsection{Micro-wire-cutting mechanism}

A novel micro-wire-cutting mechanism is designed and given in figure 3. A $\varnothing 0.02 \mathrm{~mm}$ micro brass wire starts from the wire-giving spool. It passes through a set of rubber holders, two sets of supporting rollers and four wire guides to reach the wire-receiving spool. Two sets of vertical wire guides allow cutting by the vertical wire, while the other two horizontal wire guides are designed for horizontal wire cutting. 


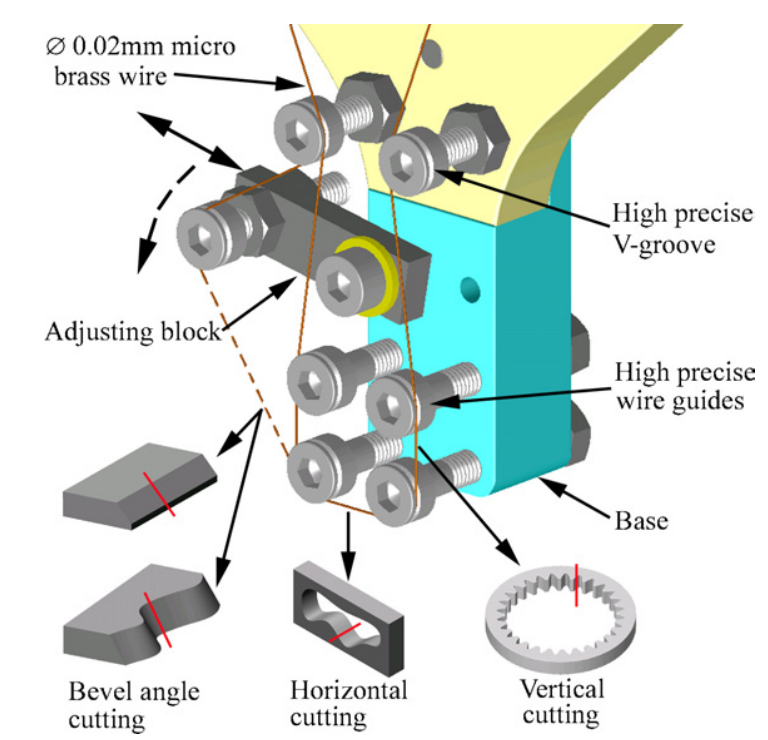

Figure 4. Partial magnification of micro-wire-cutting mechanism for horizontal, vertical and bevel angle cutting.

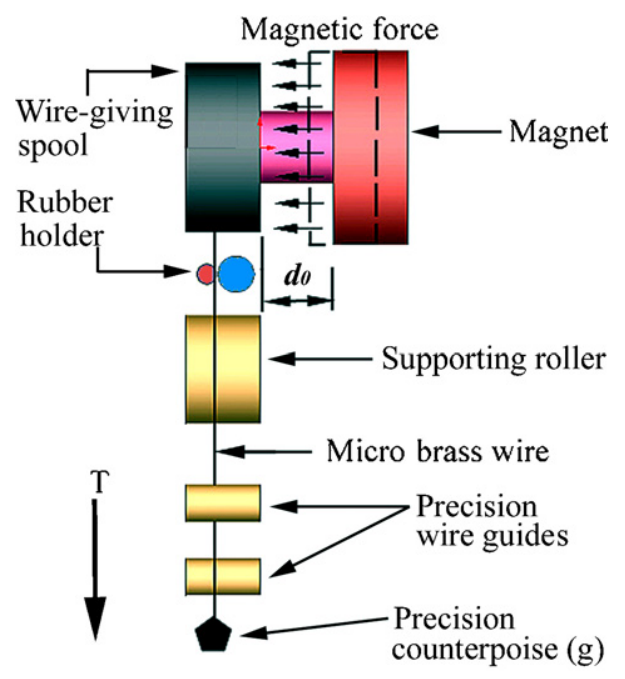

Figure 5. Tension control in micro-brass wire.

In addition, the path of brass wire can be adjusted to a slant to suit bevel angle cutting by an adjusting block (referring to figure 4). This mechanism can be mounted directly on the front face of the spindle head, and it can rotate with respect to a vertical hinge. Three kinds of control action are taken into consideration for the stability of wire movement along its path, which are tension control, velocity control and vibration control.

2.2.1. Tension control in the micro brass wire. The tension in the micro wire is controlled by the magnetic force method as shown schematically in figure 5. In the system, the wirereceiving spool is the driving wheel, and the wire-giving spool is the passive wheel. The micro brass wire is conveyed at an extremely slow and stable speed to the wire-receiving spool. A magnetic force device is placed a distance $d_{0}$ away from the wire-giving spool. The wire-giving spool is subjected to a larger magnetic force and hence tightens the wire when $d_{0}$ is decreased, and vice versa. Preliminary studies have revealed

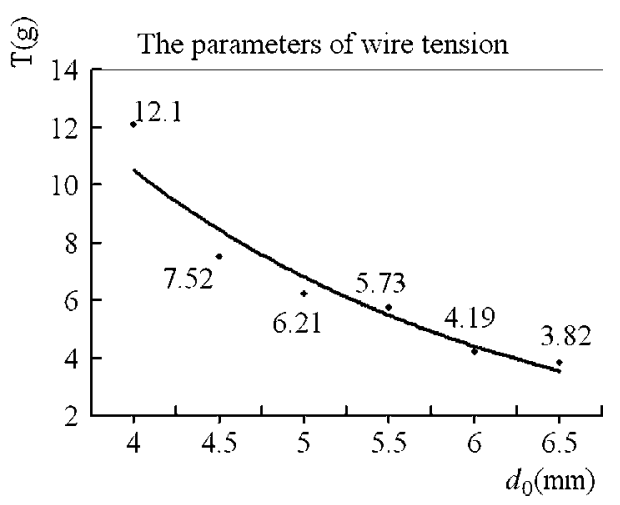

Figure 6. Tension curve for micro brass wire of the developed system.

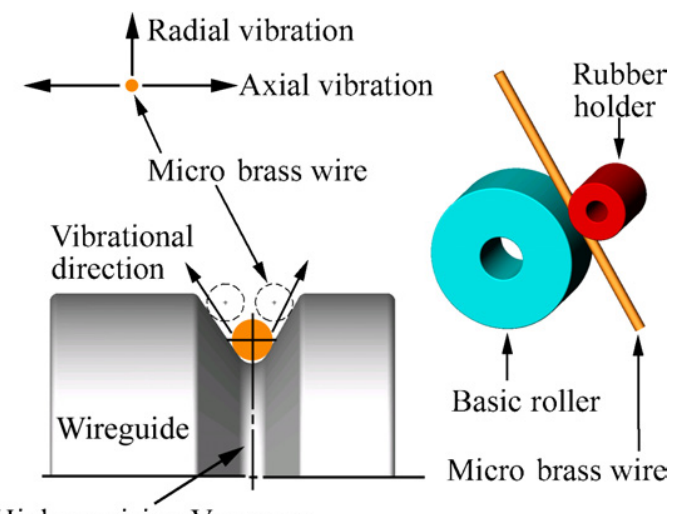

High precision $\mathrm{V}$ groove

Figure 7. Rubber holder and the state of vibration of micro brass wire in the high precision $\mathrm{V}$ groove.

that necking of a $0.02 \mathrm{~mm}$ diameter brass wire takes place when a tension higher than about $4.5 \mathrm{~g}$ is applied. A simple experiment is conducted to determine the relationship between the tension on the wire and distance $d_{0}$. A high precision counterpoise is suspended at the free end of the micro brass wire to measure its tension. The precision counterpoise will descend slowly if its weight is greater than the magnetic force. Otherwise, they are in equilibrium. Hence, the weight of the precision counterpoise must be decreased accordingly if the distance $d_{0}$ is increased so as to keep them in balance. In other words, tension in the wire is decreased with the increase in the distance $d_{0}$. Experimental data relating wire tension and the distance $d_{0}$ are given in figure 6 , where the solid curve is the regression relationship. It is found that a wire tension of $4.19 \mathrm{~g}$ is appropriate, and the corresponding $d_{0}$ of $6.0 \mathrm{~mm}$ is selected throughout our experiments.

2.2.2. Velocity control of the wire. It is expensive and difficult to drill a $0.02 \mathrm{~mm}$ diameter hole on the wire drawing diamond die to guide the wire in wire-EDM process. In the machine developed, the wire guides with a high precise $\mathrm{V}$ groove are employed instead. It is noted in the machining process that a slight variation of wire tension may lead the wire to vibrate along the axial or radial direction in the $\mathrm{V}$ groove as shown schematically in figure 7 . The probability and amplitude of vibration becomes larger under a higher wire speed condition. Hence, the velocity control of the micro wire is essential. 
In order to reduce the vibration of the wire brought about by the running of machine and the environment, a rubber holder is devised to be in contact with the basic roller along the pathway of wire as shown in figure 7 . This rubber holder functions as a vibration absorber as well as pressing the wire to prevent vibration and any other small movements.

The amplitude of vibration of the micro brass wire was observed under a high magnification toolmaker microscope. It is found that under the $4.19 \mathrm{~g}$ tension condition $\left(d_{0}=\right.$ $6.0 \mathrm{~mm}$ ), the maximum amplitudes are within $1 \mu \mathrm{m}$ in both the axial and radial directions, under the wire velocity of $30 \mathrm{~mm} \mathrm{~min}{ }^{-1}$. It is also found that a smaller distance $d_{0}$ results in a smaller hysteresis effect from the magnet. The hysteresis effect will result in the unsteady movement of the micro brass wire. To avoid the hysteresis effect and prevent the wire from necking due to high tension, the amplitude within $1 \mu \mathrm{m}$ is found to be suitable. Therefore, the wire velocity of $30 \mathrm{~mm} \mathrm{~min}^{-1}$ and the distance of $d_{0}=6.0 \mathrm{~mm}$ are selected in the following experiments.

\subsection{Pulse generating circuit and servo feed control}

In micro-EDM, the resistance-capacitance circuit (RC) is always employed as the discharge circuit because it can easily achieve a discharge current with a short pulse and a high peak [13], which leads to very shallow discharge cavity. As a result, a better surface finish than that resulting from a transistorized circuit is obtained. The RC circuit used in the machine developed is shown in figure 8 . The approach to determining an appropriate capacitance in the circuit will be discussed in section 4.

As is similar to conventional wire-EDM machines, a good servo feed control is needed to maintain constant gap for better performance of the machine. As seen from figure 8 , the current across the resistance $(R)$ becomes very small when the gap is constant and the discharge is stable. By defining this voltage on both terminals of the resistance as 'Real-time voltage $V_{R}, V_{R}$ can be taken as a parameter to reflect the gap condition in machining. A large $V_{R}$ indicates that there are more short-circuit discharges. The quantity $V_{R}$ is the product of $R$ and the current flows through the gap

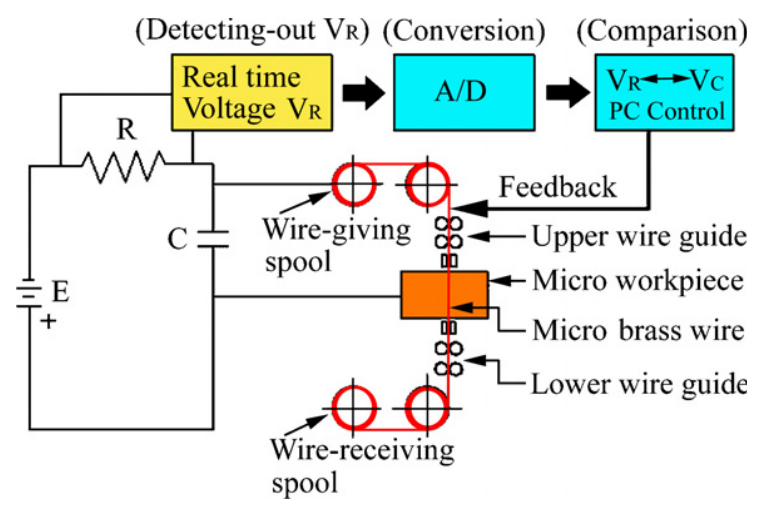

Figure 8. RC discharge circuit for micro-wire-EDM.

$(I)$, i.e.

$$
V_{R}=R I
$$

Hence, the state of the micro-wire-EDM process can be monitored by constantly measuring $V_{R}$. Since the measured $V_{R}$ is an analog signal, it is converted to digital data through an A/D converter before it is input into a PC, and then it is compared with a predetermined voltage $V_{C}$. The feedrate of the micro-wire electrode is regulated according to the variation of digital $V_{R}$. A block diagram of the control scheme is shown in figure 9 .

\section{Determination of proper capacitance of the discharge circuit}

In order to obtain an appropriate capacitance of the discharge circuit, preliminary experiments of slot cutting are conducted. Three modes of cutting are classified according to the direction in which the micro wire moves. They are top-down cutting, bottom-up cutting and horizontal cutting, as depicted in figure 10 .

The work material is $1.0 \mathrm{~mm}$ thick copper and the cutting distance is $0.3 \mathrm{~mm}$. It is cut under different discharge energy conditions. The dielectric used is lamp oil. The workpiece is submerged in the dielectric and a slow side flow of the

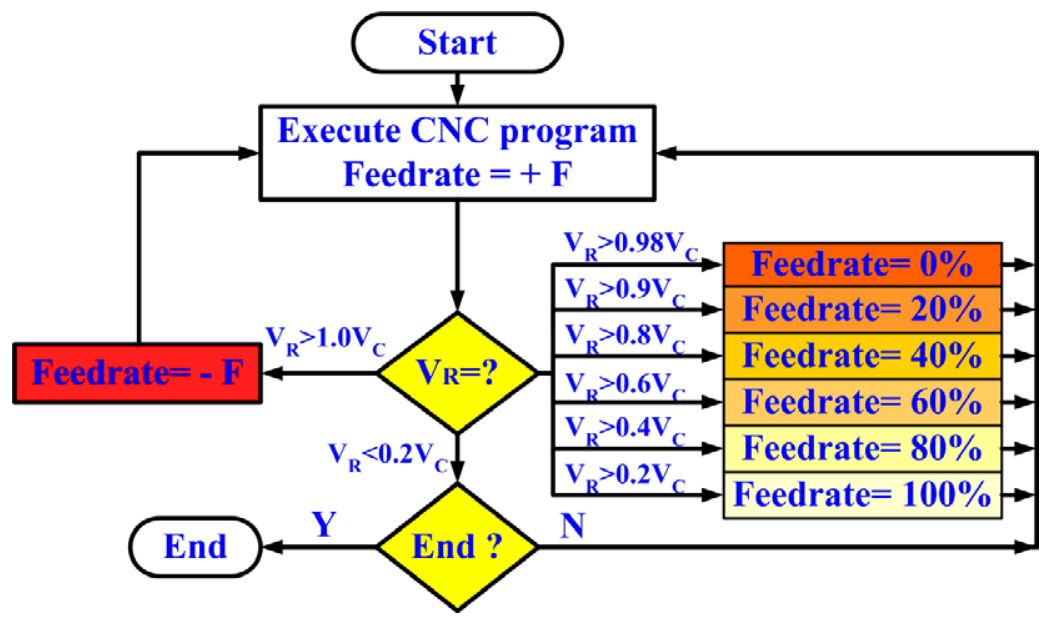

Figure 9. Block diagram of servo feedrate control. 


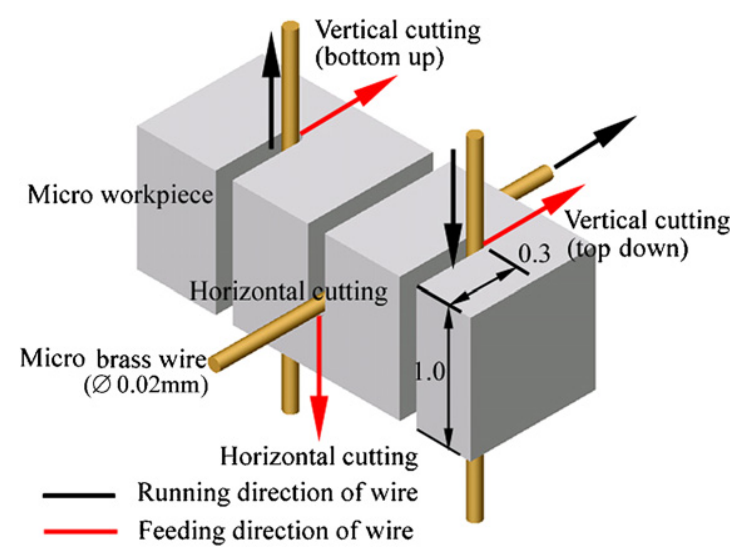

Figure 10. Three types of machining modes of micro-wire-EDM.

Table 1. Parameters used in the experiment.

\begin{tabular}{ll}
\hline Wire material & Brass wire \\
Wire diameter & $\varnothing 0.02 \mathrm{~mm}$ \\
Workpiece & Copper \\
Polarity & Negative \\
Working voltage & $80 \mathrm{~V}$ \\
Feedrate & $0.06 \mathrm{~mm} \mathrm{~min}{ }^{-1}$ \\
Cutting thickness & $1.0 \mathrm{~mm}$ \\
Cutting distance & $0.3 \mathrm{~mm}$ \\
\hline
\end{tabular}

dielectric is applied simultaneously during the machining process. The related parameters are summarized in table 1 .

The slots obtained by the three different modes of cutting are shown in figures $11(a)-(c)$. Inspecting these slots

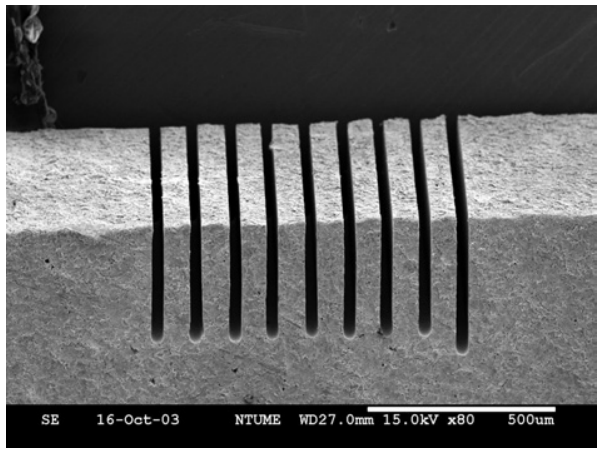

(a)

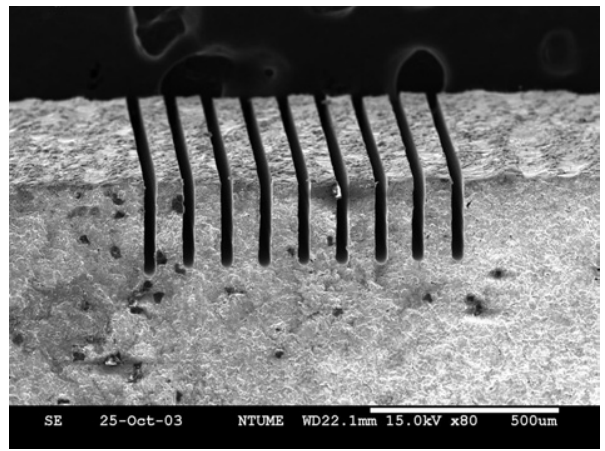

(c) under a SEM reveals that the slots satisfy the requirement of dimensional accuracy, geometry accuracy and surface roughness. Table 2 shows the slot width and the machining time under different machining modes and different discharge capacitances. From this table, it can be readily concluded that the use of a capacitance of $680 \mathrm{pF}$ results in the smallest discharge gap and minimum machining time, in other words, better performance. It is also noted that the three machining modes result in comparable machining times. These results indicate that the conditions of the removal of the debris away from the discharge gap are similar. Furthermore, the frequency of short circuits and arc discharges are also similar. Based on these results the appropriate discharge capacitance is determined as $680 \mathrm{pF}$, and it is used in machining micro parts in the following session.

The dimensional accuracy of the kerf is very important in cutting micro parts. The kerf consists of the diameter of the micro brass wire and two lateral discharge gaps. In our approach the kerf is taken as the diameter of a micro tool, and it is compensated for by proper planning of the CNC tool path. The diameter of the micro tool and the tool path compensation are depicted in figure $11(d)$. By so doing, dimensional accuracy of the machined micro parts can be kept within the position accuracy of the machine: $1 \mu \mathrm{m}$ in our case.

\section{Verification of the machining capability}

Several micro parts and micro structures are machined. The machining conditions used throughout this session are shown in table 3 . The choice of horizontal or vertical wire-cutting

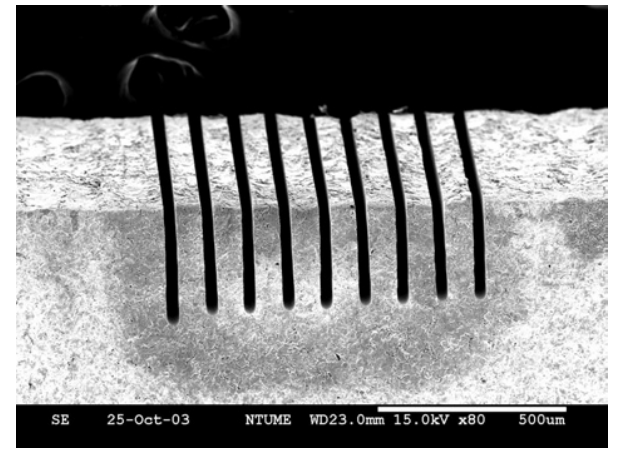

(b)

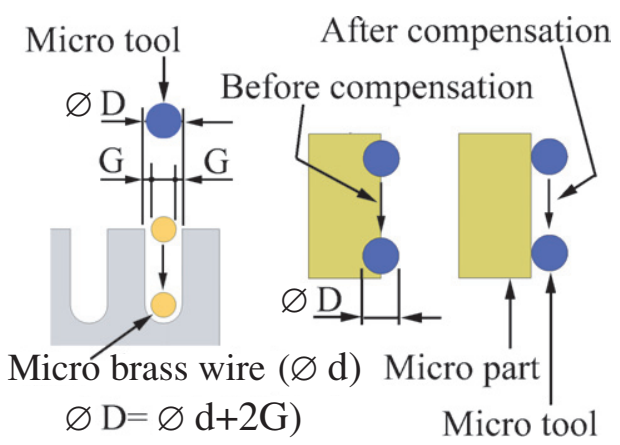

(d)

Figure 11. Samples of micro slot and the control of dimensional accuracy $(a)$ vertical bottom-up cutting mode, $(b)$ horizontal cutting mode, $(c)$ vertical top-down cutting mode, $(d)$ the diameter of the micro tool and the tool path compensation. 
Table 2. Width of slots and machining times under various capacitances.

\begin{tabular}{llllllll}
\hline & \multicolumn{3}{c}{ Width of slot $(\mu \mathrm{m})$} & & \multicolumn{3}{c}{ Machining time $(\mathrm{s})$} \\
\cline { 2 - 4 } \cline { 7 - 8 } Capacitance $(\mathrm{pF})$ & Bottom up & Horizontal & Top down & & Bottom up & Horizontal & Top down \\
\hline 240 & 31.1 & 30.9 & 33.6 & & 405 & 455 & 470 \\
330 & 30.6 & 30.5 & 33.8 & & 410 & 431 & 437 \\
470 & 30.1 & 31.3 & 32.6 & & 455 & 449 & 457 \\
$\mathbf{6 8 0}$ & $\mathbf{2 9 . 8}$ & 29.4 & $\mathbf{3 1 . 8}$ & & $\mathbf{4 0 4}$ & $\mathbf{4 0 8}$ & $\mathbf{4 2 3}$ \\
$\mathbf{7 5 0}$ & 31.1 & $\mathbf{2 9 . 3}$ & 32.1 & & 499 & 444 & 455 \\
1000 & 31.9 & 31.9 & 33.9 & & 438 & 416 & 435 \\
1200 & 30.1 & 30.5 & 33.2 & & 511 & 421 & 435 \\
1500 & 31.1 & 31.6 & 32.8 & & 454 & 430 & 450 \\
2200 & 30.7 & 32.1 & 32.8 & & 555 & 498 & 483 \\
Average & 30.7 & 30.8 & 32.9 & & 459 & 439 & 449 \\
\hline
\end{tabular}

Table 3. Machining conditions used for verification.

\begin{tabular}{lllll}
\hline Working voltage & Working capacitance & Wire velocity & Feedrate & Wire tension \\
\hline $80(\mathrm{~V})$ & $680(\mathrm{pF})$ & $0.30\left(\mathrm{~mm} \mathrm{~min}^{-1}\right)$ & $0.06\left(\mathrm{~mm} \mathrm{~min}^{-1}\right)$ & $4.19(\mathrm{~g})$ \\
\hline
\end{tabular}

Table 4. Design parameters of micro-internal spur gear set.

\begin{tabular}{llllll}
\hline Form of micro gear & & Module & Number of teeth & Pitch diameter & Cutting thickness \\
\hline Outer & Gear & $0.0270 \mathrm{~mm}$ & $24 \mathrm{~T}$ & $0.648 \mathrm{~mm}$ & $0.25 \mathrm{~mm}$ \\
\multirow{2}{*}{ Internal } & Pinion & & $12 \mathrm{~T}$ & $0.324 \mathrm{~mm}$ & \\
& Gear & \multirow{2}{*}{$0.0624 \mathrm{~mm}$} & $28 \mathrm{~T}$ & $1.747 \mathrm{~mm}$ & $0.25 \mathrm{~mm}$ \\
& Pinion & & $10 \mathrm{~T}$ & $0.624 \mathrm{~mm}$ & \\
\hline
\end{tabular}

depends on the difficulty of clamping the micro workpiece to the table.

\subsection{Vertical wire-cutting examples}

A vertical wire arrangement is used to manufacture micro internal gear and micro outer gear since both the clamping of workpiece and $\mathrm{CNC}$ path planning are easier to accomplish. The machining mode can be seen in figures 4 and 10 . The design parameters of the micro gear set being tested are given in table 4 . The finished micro internal gear and the micro outer gear are shown in figure 12.

It can be seen from figures $12(a)-(c)$ that there exists no taper angle along the depth of the teeth of the gear, and very good level of accuracy is achieved. For comparison purposes, a micro internal gear machined by EDM milling followed by WEDG of the micro electrode is shown in figure 12(e), and the partial magnification of one tooth is given in figure $12(f)$. The taper angle along the width of the teeth is obvious. This is caused by the wear of the micro electrode inevitable in EDM, resulting from arc discharges, caused by debris that has not been fully flushed away.

The surface inspected under SEM is shown in figure 12(d). The average diameter of a micro discharge cavity is about $4.0 \mu \mathrm{m}$, and the relationship between the single-shot discharge cavity and the surface roughness in $R_{\max }$ is [13]

$$
R_{\max }=2 h_{1}+h_{2}, \quad d=(10 \sim 20) h_{1}
$$

where $d$ and $h_{1}$ are the diameter and depth of the single-shot discharge cavity, respectively. The quantity $h_{2}$ is the protrusion height around the discharge cavity, and it is about $0.2 \mu \mathrm{m}$.
Taking $d=4.0 \mu \mathrm{m}$, and if $d=18 h_{1}$, then

$$
R_{\max }=2 \times 4.0 / 18+0.2=0.64 \mu \mathrm{m}
$$

i.e. the roughness on the surface of the micro internal gear is about $R_{\max }=0.64 \mu \mathrm{m}\left(R_{a}=0.16 \mu \mathrm{m}\right)$.

\subsection{Horizontal wire-cutting example}

Using the machine developed, micro workpieces can be cut by a horizontal wire arrangement if vertical wire cutting is not appropriate. The micro rack is one of the examples. The machining mode can be seen in figures 4 and 10. The micro rack with a designed circular pitch of $0.1335 \mathrm{~mm}$ is displayed in figure $13(a)$. Measurement under the SEM microphotograph reveals that the circular pitch is $0.1330 \mathrm{~mm}$ (referring to figure 13(b)). Hence, the dimensional accuracy achievable is within $1.0 \mu \mathrm{m}$.

\subsection{Horizontal and vertical wire-cutting example}

To further test the capability of the machine developed, a miniature pagoda with a special structure as shown in figures $14(a)$ and $(b)$ is taken as another example. Using the conventional vertical cutting mode, the micro workpiece needs to be unloaded, turned $90^{\circ}$ and repositioned for subsequent top and bottom sides cutting after its right and left side structures have been machined. If the workpiece is mounted vertically, the horizontal wire-cutting mode can be employed. The right and left sides of the pagoda are cut first. Following this, the wire-cutting mechanism is rotated $90^{\circ}$, and then the other two sides cutting is conducted using the same horizontal wirecutting mode. Either of the above-mentioned approaches is 


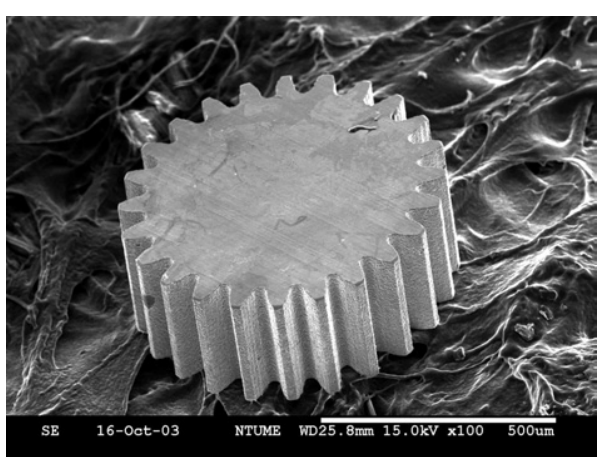

(a)

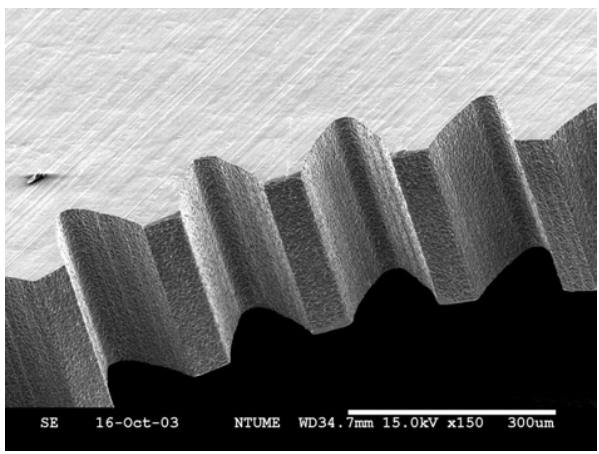

$(c)$

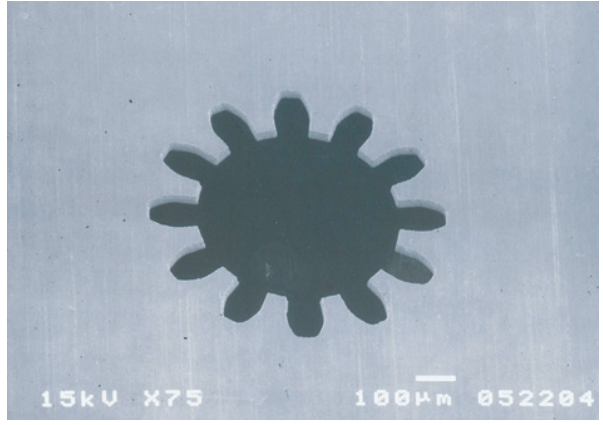

(e)

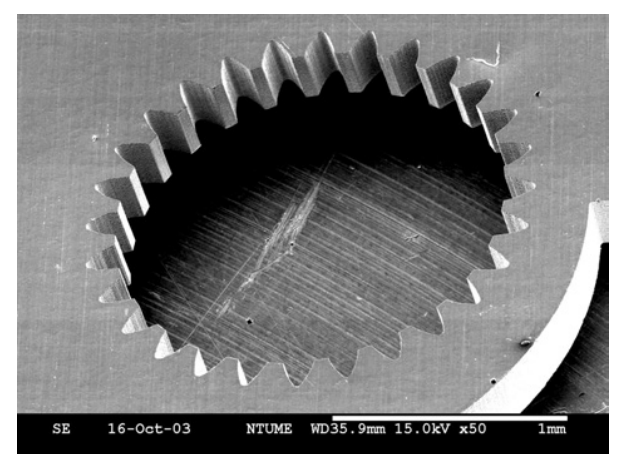

(b)

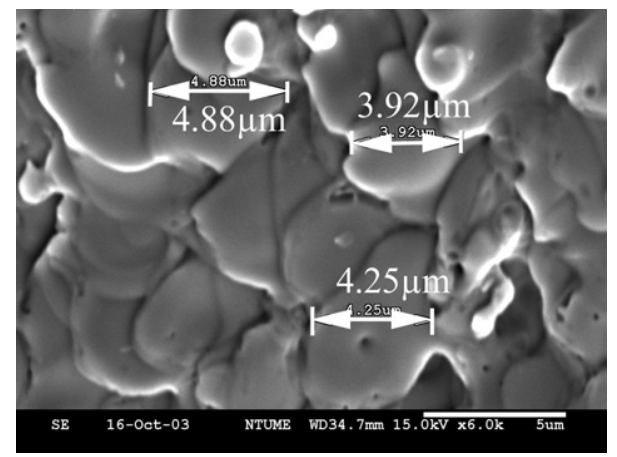

(d)

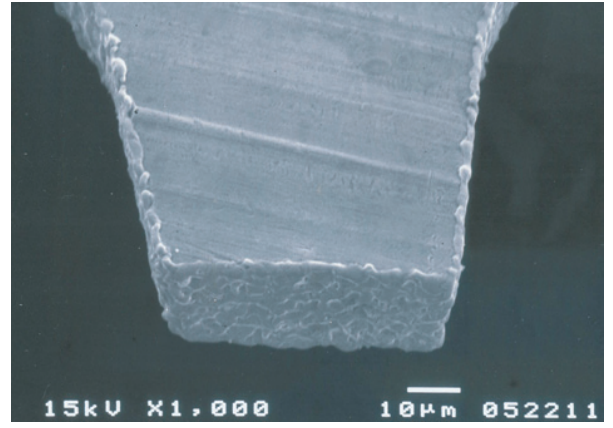

$(f)$

Figure 12. The machined micro gear $(a)$ the micro outer gear, $(b)$ the micro internal gear, $(c)$ partial magnification of the micro internal gear, $(d)$ discharge cavity of the micro internal gear, $(e)$ the micro internal gear by micro-EDM milling, $(f)$ the partial magnification of one tooth by micro-EDM milling [6].

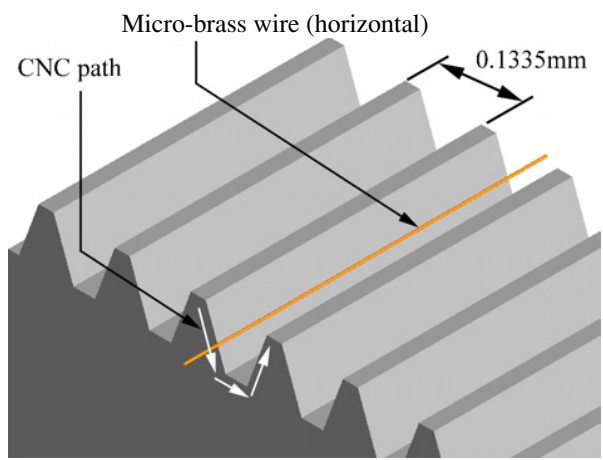

(a)

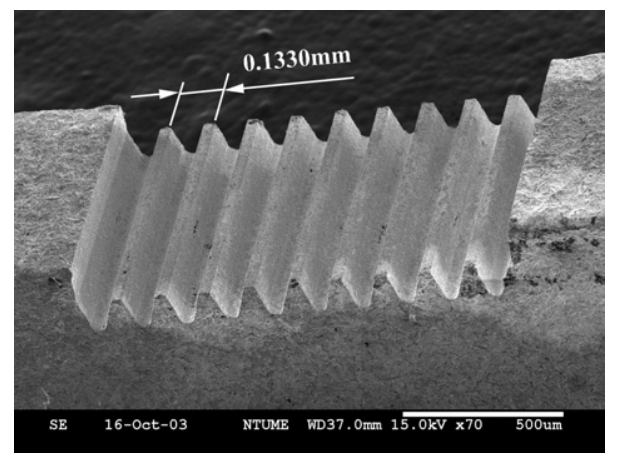

(b)

Figure 13. The designed and machined micro rack $(a)$ the design of the micro rack by 3D CAD, $(b)$ the SEM microphotograph of the finished micro rack. 


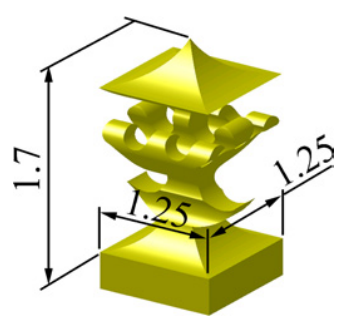

(a)

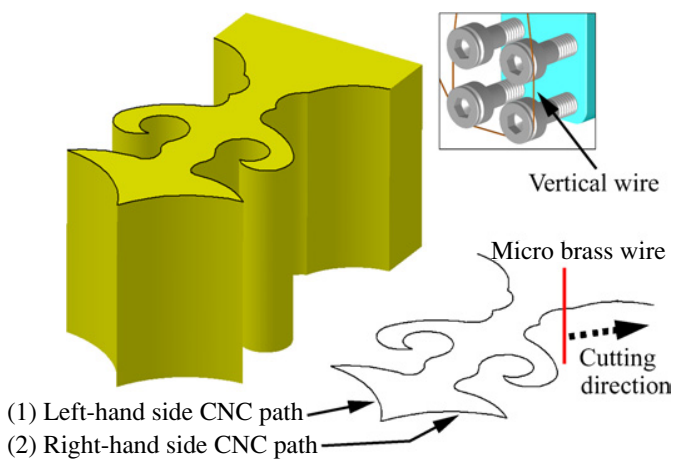

(c)
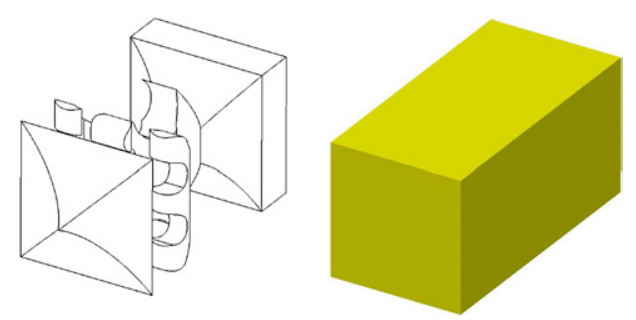

(b)

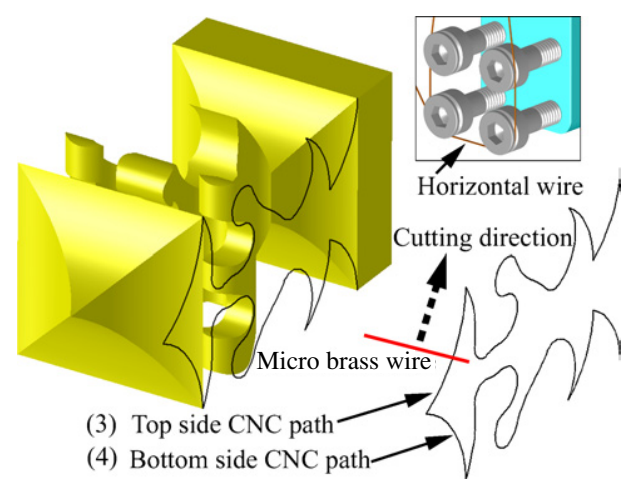

(d)

Figure 14. The design and CNC path scheme of the miniature pagoda $(a)$ design of the miniature pagoda by $3 \mathrm{D}$ CAD, $(b)$ another view angle and the work material, $(c)$ left side and right side $\mathrm{CNC}$ paths of the micro pagoda, $(d)$ top side and bottom side CNC paths of the micro pagoda.

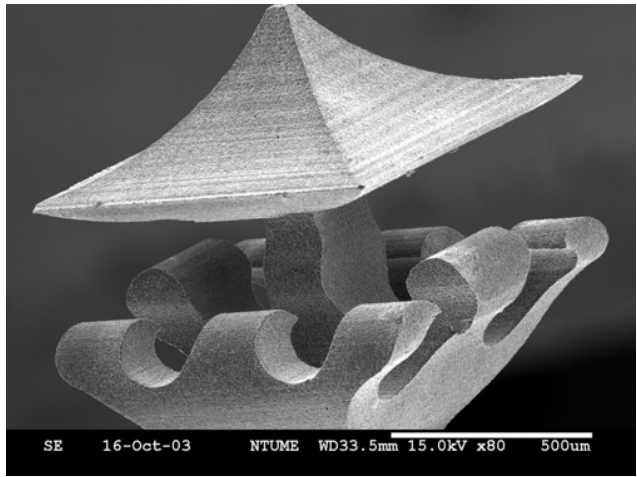

(a)

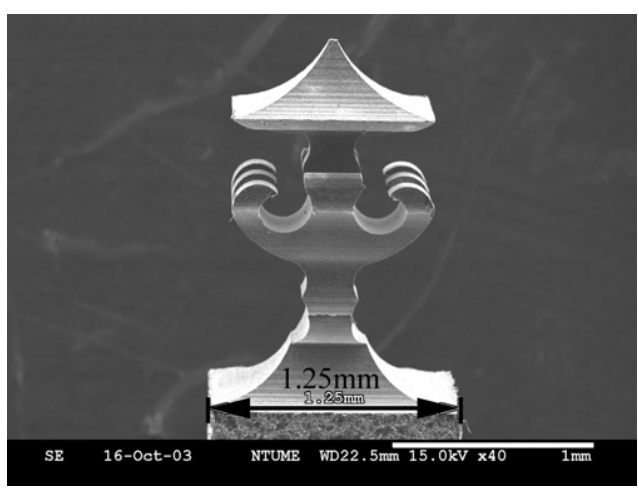

$(c)$

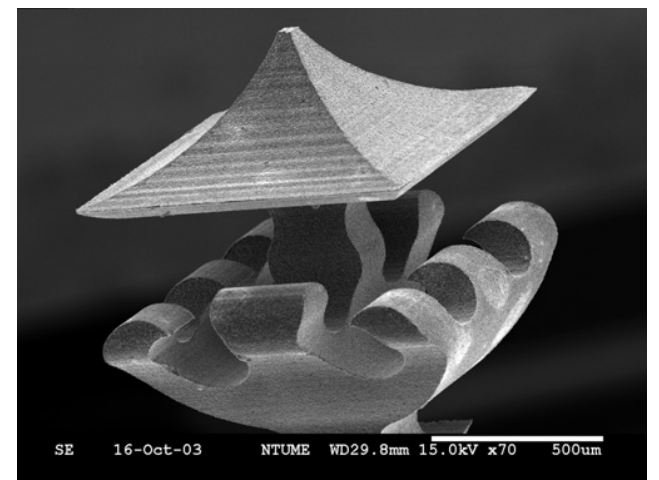

(b)

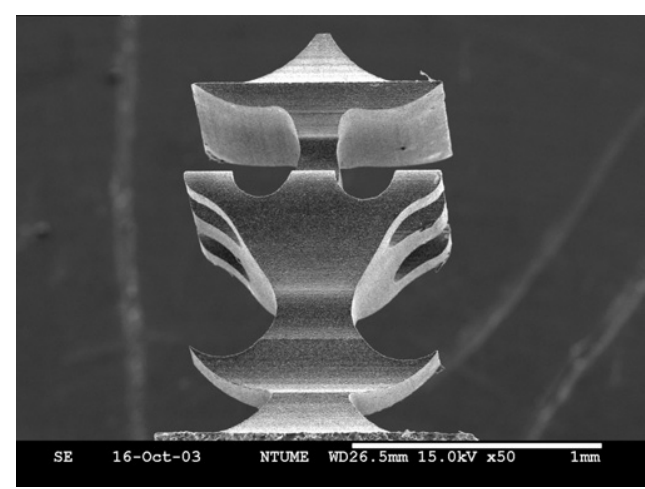

(d)

Figure 15. The machined miniature pagoda $(a)$ partial magnification, $(b)$ partial magnification of another angle view, $(c)$ front view, (d) bottom view. 
tedious and time consuming. The positioning accuracy is also very difficult to guarantee. In contrast, the task can be easily accomplished by employing vertical and horizontal wire-cutting modes sequentially (referring to figures 4 and 10). Specifically, the CNC path consists of four parts, namely the left, right, top and bottom side cutting, respectively. First, the right and left sides of the pagoda are cut by the vertical wire according to the planned CNC path as displayed in figure 14(c). Next the top and bottom sides are cut using the horizontal wire as depicted in figure $14(d)$. It should be noted that miniature pagoda is not unloaded, moved and repositioned until it is finished.

The finished machined part is shown in figures $15(a)-(d)$. The material used is 6061 aluminum alloy. To improve the flushing of the debris, the workpiece is submerged in the dielectric during cutting with a slow flow application of the dielectric (in our case it is lamp oil). The machining time is about $1 \mathrm{~h}$ for each side of the miniature pagoda.

\section{Conclusion}

A novel mechanism is designed and a high precision tabletop versatile CNC wire EDM for making micro parts is developed. Approaches for wire tension control, velocity control, vibration control and servo feed control are proposed and implemented. Various micro parts and structures of sizes between 0.03 and $2.0 \mathrm{~mm}$ are cut successfully. The use of the developed machine increases the machining flexibility. The taper angle of the machined part which is inevitable in the existing micro-EDM process can be prevented. In addition, a better machining efficiency, dimensional accuracy and surface finish are achieved. The machine developed provides another alternative for manufacturing micro parts, particularly the $3 \mathrm{D}$ intricate parts, and is expected to contribute to the field of MEMS.

\section{References}

[1] Masuzawa T 2000 State of the art of micromachining Ann. CIRP 49 473-88

[2] Dario P, Carroua M C, Croce N, Montesi M C and Cocco M 1995 Non-traditional technologies for micro fabrication J. Micromech. Microeng. 5 64-71

[3] Masuzawa T, Fujino M and Kobayashi K 1985 Wire-electrodischarge grinding method Ann. CIRP 34 431-4

[4] Yu Z Y, Masuzawa T and Fujino M 1998 Micro EDM for three-dimensional cavities: development of uniform wear method Ann. CIRP 47 169-72

[5] Bleys P, Kruth J P and Lauwers B 2004 Sensing and compensation of tool wear in milling EDM J. Mater. Process. Technol. 149 139-46

[6] Chen S T 1997 Development of vertical micro CNC electrical discharge machining center and research of micro 3D parts machining Master thesis National Yunlin Science \& Technology University, Taiwan (in Chinese)

[7] AGIE Ltd, Wire-Cut EDM web page http://www.agie.com/english/index_e.html

[8] CHARMILLIES Ltd, Wire-Cut EDM web page http://www.charmilles.com/en/prod_wire.shtml

[9] FANUC Ltd, Wire-cut EDM web page http://www.fanuc.co.jp/ en/product/robocut/alpha0pic/index.html\#wire

[10] SODICK Inc., Wire EDM web page http://www.sodick.com/Products/all_edm.htm

[11] Kinoshita H and Hayashi Y 1996 Study in micro wire EDM EDM Technol. 2 24-9

[12] Yan M T, Huang C W, Fang C C and Chang C X 2004 Development of a prototype Micro-wire-EDM machine J. Mater. Process. Technol. 149 99-105

[13] Saito C 1979 The Construction and 100\% Operational Skills of EDM (in Japanese) Mitsubishi Electric Ltd pp 40-69 